\title{
An Interdisciplinary Perspective on Education Service Systems
}

\author{
Christina Tay \\ Chinese Culture University, Taipei, Taiwan \\ Christina@sce.pccu.edu.tw
}

\begin{abstract}
The increased complexity in education systems has given rise to a number of intersecting trends and calling for a discipline to integrate across academic silos. As the concept of service innovation advances more rapidly into education services; industry, government, and academy are awakened to the concept of embedding services innovation. This theoretical paper offers an integrated framework for education systems (IFES) covering two intersecting dimensions where service innovation and service science can take place. As an effort to contribute in the area of service innovation and service sciences, an interdisciplinary approach is applied, interconnecting an array of competences across the different stakeholders. It is hypothesized that to increase productivity in education industries, interconnecting knowledge and resources from diverse areas and across different stakeholders through the co-lineation of four dimensions: (1) information, communications and technology; (2) skills and tools; (3) people and attitudes; (4) systems, processes and management; are essential to creating service innovation. This paper contributes a perspective of interconnectivity balanced with harmony that are crucial for effective productivity and service innovation by adopting a service science approach.
\end{abstract}

Keywords: service science, productivity, service innovation, service quality, education.

\section{$1 \quad$ Introduction}

As societies become more diverse, individualistic and more educated, the various stakeholders in the education system also become more demanding. The importance of diverse local contexts can only be expected to increase in order to cope with such externalities. Education services in institutions are increasingly expected to ensure high quality, efficient, equitable and innovative education. At the same time, the education service sector has also become a place of burgeoning economic activities and one of the fastest rising stars contributing to Gross Domestic Product (GDP). First, in developed economies, and now in many developing economies as well, the education sector injects into the GDP of many developed economies. For Singapore, New Zealand, Australia, the U.K., the U.S. and Canada, the education sector contributes $1.9 \%, 1.13 \%, 1.06 \%, 0.4 \%, 0.5 \%, 0.25 \%$ to their GDPs [2], [5], [6], [13]. Due to such ascendance, industry, government, and institutions have awakened to the 
realization that embedding the concept of service innovation in the education sector is crucial to enhancing productivity as it contributes generously to the economic growth of education institutions as well as the national economies.

Productivity and service innovation levels in the education industry are relatively slow to develop owing to the complexity of its system resulting in its stakeholders to be less satisfied with the current assessment and distribution of value that they feel should be attainable. For example, the number of intangible units such as total number of credit hours of education produced, the number of degrees conferred and the number of courses offered by a service provider are normally referred to as outputs in service productivity. The downside of such an assessment often results in service providers being overly-focused on 'producing' credit hours, degrees, and courses rather than bundling offerings that precludes elements that matter to its stakeholders like instruction, credentialing, accreditation, student support and services during the period of their academic studies, student career services and placement prior to graduation, alumni socialization and connectivity after graduation to produce better end results rather than lead to an improvement in calculable outputs such as credit hours, degrees conferred or courses offered.

The emergence of the service science discipline creates new opportunities to study and explore transformations in education services, because it is such an important actor in knowledge economies. The providence of education services is now seen through the lens of multidisciplinary studies that converges and interconnects to create greater productivity. Service science offers a fresh perspective on the challenges faced by service providers when productivity issues are being challenged. Thus, service science emerges as a discipline that coagulates a loosely coupled of networked entities by attempting to interconnect and hold together trust propositions by applying knowledge and resources aimed at creating mutual benefits and more sustainable service-for-service interaction patterns amongst the stakeholders in an entity. Service science is motivated by a lack of integrated, foundational knowledge to inform its normative goal of assisting organizations in the process and provision of service innovation in order to realize more predictable outcomes [15]. Diversity is seen as enabling the different actors to learn from each other that enables greater productivity in the entity.

Service science seeks the elements such as those aforementioned and examines them scientifically, investigating them through the lenses of existing academic disciplines to raise productivity. It also aims to create win-win value propositions that interconnect all the stakeholders including parents, faculty, deans, heads of departments, administrators, owners, regulatory bodies(e.g. Ministry of Education, Accreditation Boards), community leaders, in conjunction with skills, technology, rules and policies improving productivity, quality, sustainability, learning by molding them to become strong backbones of a service provider through the mathematical modeling of business processes. [9] suggest that the key to understanding the exchange of resources within service systems is found in the distribution of competences, such as knowledge and skills, among service systems and understanding the value propositions that connect such systems[17]. Education is viewed as a service system that has been re-imagined as a continuous improvement process by service scientists [16]. 
Nevertheless, an integrated framework on education systems (IFES) binding several disciplines is lacking in existing literature in service sciences. In addition, literature examining service science in the education service industry is seriously lacking In this paper, the service science discipline is utilized to integrate across academic silos and advance service innovation more rapidly into the area of the education industry by presenting an IFES framework of service science web that interconnects knowledge and resources from diverse areas and the different stakeholders, embedding the core notion of continuous improvement with the final aim of optimizing productivity, enhancing quality, creating sustainability, stimulating learning with the final aims of creating service innovation in an entity. Then, in the third section, issues and opportunities for new managerial knowledge for servicesoriented systems are explored through the (a) information, communication and technology, (b) skills and tools, (c) people and attitudes, and (d) systems, processes and management perspectives. The fourth section explains the interconnections and relationships between the input and output factors as prescribed in the third section. The last section then concludes with some recommendations.

\section{IFES Framework of Service Science Web Interconnectivity}

In contrast to applying manufacturing and service orientations to service organizations, little scholarly attention has been given to the applying service orientations to education services, a sector of burgeoning growth in many developed countries [3-4], [14]. In this section, a framework that captures the complex relationships amongst stakeholders to produce knowledge and resources that advance service innovation is presented. An integrated framework on education systems(IFES) is modeled to present the complex service science web of interconnectivity that holds together knowledge and resources essential to creating mutual benefits amongst the various stakeholders in the education service industry.

The IFES framework is aimed at interconnecting the diverse competences of the various stakeholders with the final aims of developing a more sustainable service-forservice interaction patterns amongst them. The y-axis of the IFES framework takes on a multidisciplinary approach that coagulates the interests of industry, academia and government at aims enhancing and/or producing service innovation in the education industry. If the interests of such actors are not considered, the likelihood of success in service innovation is going to be low. Actors gather information and knowledge in a multi-disciplinary manner, from business administration, engineering, information science, socio-informatics, and computer-adaptive systems. The stages of service innovation is presented on the $\mathrm{x}$-axis where ideas for service innovation develops from an abstract stage to a more concrete stage as the actors in the IFES framework interact with each other. As we traverse through the inner levels of the IFES framework, an aggregate effect occurs across the two inner circular dimensions where the effects present at the previous level(s) will also be present at the subsequent level(s) of analysis in order to optimize productivity, enhance quality, create sustainability and stimulate learning with the final aim to create service innovation. 

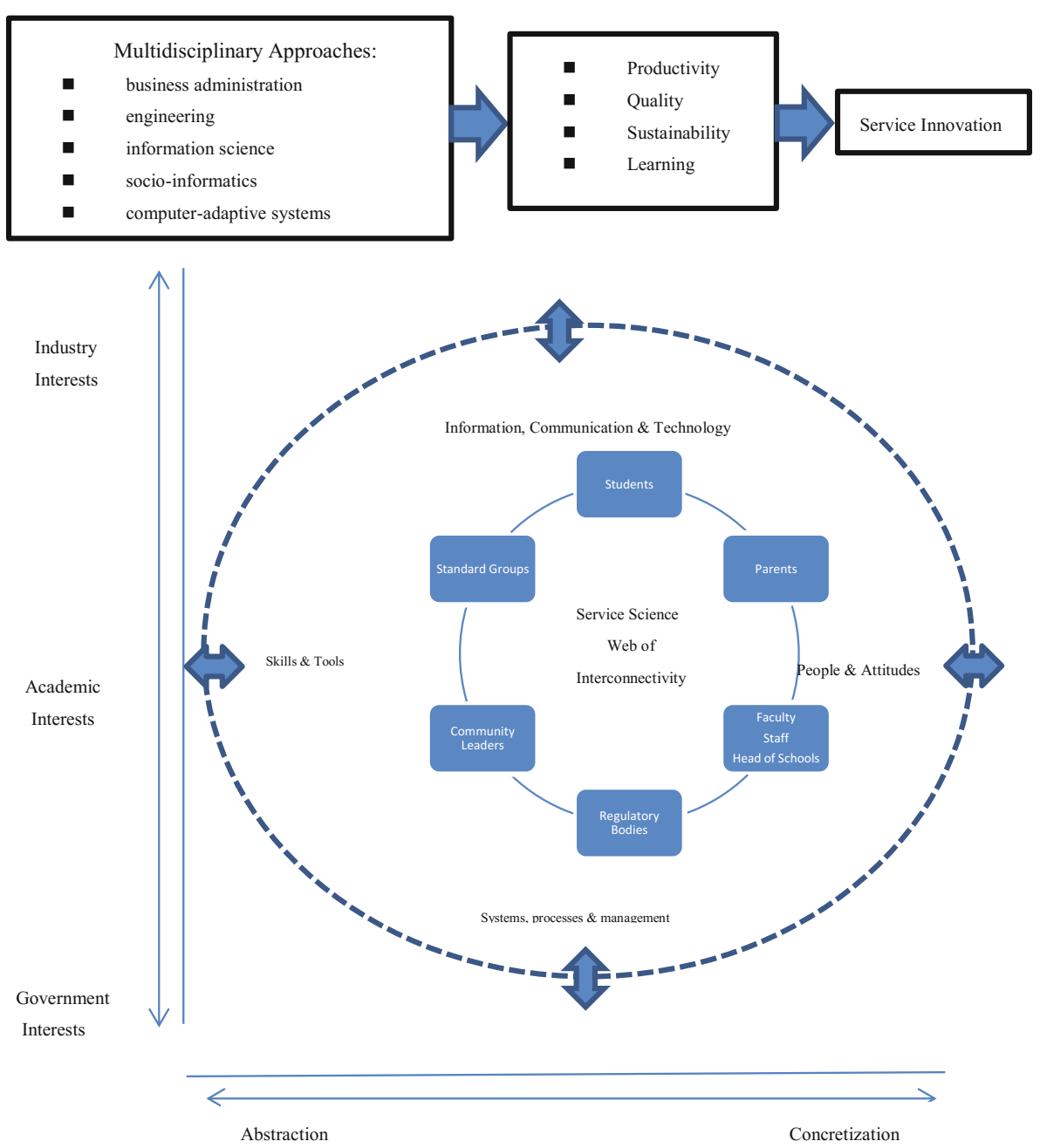

Stages of Service Innovation

Fig. 1. An integrated framework on education systems (IFES)

The inner framework works along two dimensions. The first inner dimension involves stakeholders who interact with one another directly or indirectly. The stakeholders may be from different parts of the same organization, or across a couple of different organizations. The second dimension is how these stakeholders utilize 
their different competences. The inner circle of Fig. 1 shows first dimension: the stakeholders. Typical stakeholders have private profit incentive-driven and social welfare-driven considerations related to the economic, organizational, human, and technological issues that may arise [1]. In this paper, the term stakeholder refers to an agent who has interest in a service entity and who may be able to affect change through his/her own actions, or is affected by other change agents due to the actions of another stakeholder. The resulting changes vary in their impact dimensions on service productivity and service innovation.

The ripples of our inner circle portray the effects of the different stakeholders upon each other due to their individual actions. [8] have characterized these contrasting stakeholder roles as value makers and value takers, as they are at opposite ends of the spectrum of production and consumption. One example of contrasting stakeholder roles are student \& parent stakeholders(value takers) as opposed to faculty, staff and head of schools(value makers) may hold conflicting goals; for example, lower school fees versus maximizing payback on services provided to stakeholders. The same holds true for regulatory bodies(value takers) versus head of schools(value makers) where the former may be interested to regulating or standardizing processes to optimize social welfare, whilst the latter may be more interested in possessing greater flexibility in their operational processes in order to achieve meet the agile needs of stakeholders, faculty and staff. From the student \& parent stakeholders (value takers) perspective of the latter, regulatory bodies (e.g. the Department of Education, Accreditation Bodies) are the value makers for them.

Another class of stakeholders may not play a direct role in consumption of education services, but may represent the views of other stakeholders. These are the community leaders (value takers/makers) who may interact with faculty, staff and head of schools (value makers/takers). Their value derives from carrying out or preserving the interests of other stakeholders related to the education entity so that services offered possess continuous improvement qualities and that the rights of other stakeholders are heard and protected. The concept embedded in the IFES framework is that no stakeholder group is considered more important than the other but one of opposing interests and shared concerns.

The final outputs in service productivity and service innovation emphasize on harmony between the different stakeholders whilst interconnecting their different competences: information, communications and technology; skills and tools; people and attitudes; systems, processes and management. The interconnectivity process of attempting to hold together knowledge and resources could mean some sacrifices will have to be made, career paths may be changed and skills enhanced. There are renewed endeavor for an integrated discipline in modern education entities of today. Thus, this paper contributes a perspective of interconnectivity balanced with harmony in productivity elements that are crucial for effective productivity and service innovation.

The outer circle of Fig. 1 shows the second dimension: the competences of the different stakeholders. In the IFES framework, the cascading effects of both dimensions are required to drive the creation and diffusion of de facto outputs. Without them, the forces that are needed to evolve greater productivity cease to exist. 
The IFES captures the countervailing forces and effects of these processes. The concept of synergizing the countervailing forces and effects of these processes is represented with a circular design. Each arrow represents a unique force that influences service productivity which could, in return promote service innovation, and vise-versa. The inner circle reflects the reality and complexity as the various stakeholders interact with each other. Complexity increases with the addition of new stakeholders and as more stakeholders interact with each other. The ripples on the circles illustrate the cascading effects of the stakeholders and competences as these forces interconnect and interact with each other. Since it is possible that these outcomes may not occur during all interactions, ripples are used instead of solid lines to provide an accurate depiction.

To produce the desired output consisting productivity, quality, sustainability, learning and service innovation, the co-lineation of the various dimensions in the inner and outer circles must occur in a harmonious pattern. The noise produced during this dynamic interaction must be separated from signals in order to differentiate what makes up the desired outputs.

\section{The Interconnectivity between Inputs and Outputs}

By developing a service mindset, education institutions are more easily able to recognize the interactive nature of services output. Each stakeholder in the system (whether student or institution) must be aware that the outcomes produced is coproduced through a shared vision that is of mutual benefit to all actors. The economic definition of productivity is, fundamentally, the relation between the physical quantities of outputs and the physical quantities of inputs[10].Service quality is where both input and output quantities are adjusted to yield the intended results.

The old adage of productivity represents some measure of the ratio of a producer's output to input. For example, completion-to-enrollment ratio, time to degree, cost per credit/degree, student-faculty ratio and cost or "profit" per faculty member. But, such conventional perspectives do not address the perspectives of the different stakeholders. Taking an example of student-faculty ratio, the problem with such a conventional approach to boosting productivity is its failure to consider the inputs of stakeholders on student perception of teacher quality into the process as well as the outputs experienced by the stakeholders such as student learning satisfaction. Instead, its approach would be to try to maximize student-faculty ratio by depleting student numbers or increasing faculty number and/or by setting stringent performance standards for faculty, which could result in the suffering of one stakeholder (teacher subject to more stringent performance standards) at the expense of innovation in teaching, which can be depicted as a form of service innovation.

Thus, such a conventional approach to productivity takes into account, the customer's perspective - defined as the ratio of the service output experienced by a customer to the output experienced by a customer as a participant in service production - suffers when managers in service-producing businesses blindly mimic the productivity improvement methods of their peers in product- producing 
businesses[11]. A customer(student's) perspective on productivity, when considered separately, often ends up with one stakeholder at odds with the other; increasing productivity for one at the stake of the other.

A totally different approach to productivity has to be taken to obtain a global measure of how well a service provider uses resources to create outputs in the form of acceptable perceived quality and customer value. In services, it is not only the inputs that are difficult to calculate, it is also difficult to get a useful measurement of the outputs. Hence, productivity cannot be understood without taking into account the interrelationship between the use of inputs or production resources and the perceived quality of the output produced with these resources[7].

The service science perspective presented in the IFES framework offers an interconnectivity perspective that examines productivity from the different stakeholder, where stakeholders benefit from the synergies of their respective competencies. The outer circle of Fig. 1 presents a conceptual IFES framework that captures this very essence of synergizing the competences of the various stakeholders and portrays the central role of service quality in linking the two. The arrows from the core of the IFES framework that lead to the outer circle implies how the inputs from the stakeholders along with their competences influence service quality. Service quality, in return, influences the outputs of the different stakeholders.

In services, productivity and service innovation cannot be separated. Through inputs such as (a) information, communication and technology, (b) skills and tools, (c) people and attitudes, and (d) systems, processes and management perspectives; stakeholders participate in the derivation of productivity and service innovation. They may also have an impact on how fellow stakeholders participate in the process and perceive the quality of the service produced. Such an interaction-induced stakeholder system integrated with their respective competencies contributes to productivity and service innovation.

The interrelationship depicted here reflects a constant interactive relationship amongst the stakeholders. Service productivity and service innovation is rather dependent on the progress of relationships amongst these actors, at the same time involves co-learning experiences of both or all parties. In the process, the various stakeholders will learn how to interact with one other so that service inefficacies, service quality deficiencies and information asymmetries can be minimized and so as not to create unnecessary costs for both or all parties. As this interconnectivity pattern continues, the stakeholders attain greater experience and learn to be able to more effectively participate in outputting greater productivity and enhancing service innovation values. During this process, the stakeholders also learn more about each other's competences that allows increased productivity and service innovation.

It is important for service productivity that one realizes that customer relationships are learning relationships, where both parties learn about each other, and that they last over a long period of time [7], [12]. The development of service productivity is one of a mutual learning experience consisting constant interactions amongst its stakeholders, whilst understanding their individual competences along the way. 


\section{Conclusion}

The service industry evolves in a dynamic environment where different stakeholders may have conflicting expectations of what makes up productivity and service innovation, thus, making it harder than ever to separate noise from signals. This paper presented a framework from a service science perspective which utilizes an interdisciplinary approach to integrate across academic silos and advance service innovation more rapidly into the area of the education industry. The IFES framework interconnects knowledge and resources from diverse areas and across the different stakeholders, embedding the core notion of continuous improvement with the final aim of optimizing productivity, enhancing quality, creating sustainability and stimulating learning with the final aims of creating service innovation.

The IFES framework emphasizes the multiple roles of different stakeholders in an education entity including stakeholders, parents, faculty, staff, regulatory bodies (e.g. Ministry of Education, Accreditation Boards), community leaders and standard groups. No stakeholder group is considered more important than the other. Instead, the perspective under-planted in this IFES framework is one of opposing interests and shared concerns. The IFES framework presented points out how the co-lineation of information, communications and technology; skills and tools; people and attitudes; systems, processes and management; can find an important place in the founding of emerging discipline of service science.

In the process of creating greater productivity and enhanced service innovation, stakeholders will learn how to interact with one another as well as about others' individual competences. Such interrelationship is one that emphasizes on harmony amongst the various stakeholders, whilst interconnecting their different competences. During the interconnectivity process of attempting to hold together knowledge and resources for the mutual benefits for the various stakeholders could mean some sacrifices will have to be made, career paths may be changed and skills enhanced. There are renewed endeavor for an integrated discipline in modern education entities of today. Thus, this paper contributes a perspective of interconnectivity balanced with harmony that are crucial for effective productivity and service innovation in an increasingly complex service system by undertaking a service science approach.

\section{References}

1. Bardhan, I.R., Dermirkan, H., Kanna, P.K., Kauffman, R., Soufstad, R.: An Interdisciplinary Perspective on IT Services Management and Service Science. Journal of Management Information Systems 26(4), 13-64 (2010)

2. Boag, S.: New Zealand punching above its weight in Export Education. Media Release, Education New Zealand (November 26, 2010), http: / /www. educationnz.org.nz/comm/Mediarealeases / Punching $\% 2$ Above $\% 2$ Weight-26-11-08.pdf (retrieved on November 10, 2013)

3. Bowen, D.E., Siehl, C., Schneider, B.: A Framework for Analyzing Customer Service Orientations in Manufacturing. Academy of Management Review 14(1), 75-95 (1989) 
4. Castelacci, F.: Technological paradigms, regimes and trajectories: Manufacturing and service industries in a new taxonomy of sectoral patterns of innovation. Research Policy 37, 978-994 (2008)

5. Crawford, R.: Universities Key to Building Export Education Industry, Te Pokai Tara (February 20, 2009), http: / /www . universitiesnz . ac .nz/node/364

6. Douglass, J.A., Edelstein, R., Hoaraeu, C.: US Higher Education as an Export: It is about the money, but also much more, Center of Studies in Higher Education (April 28, 2011) (retrieved on November 10, 2013)

http: / / cshe. berkeley. edu/news / index.php?id=89

7. Grönroos, C., Ojasalo, K.: Service productivity: Towards a conceptualization of the transformation of inputs into economic results in services. Journal of Business Research 54(4), 414-423 (2004)

8. Kauffman, R.J., Walden, E.: Economics and electronic commerce: Survey and directions for research. International Journal of Electronic Commerce 5(4), 5-116 (2001)

9. Maglio, P.P., Spohrer, J.: Fundamentals of Service Science. Journal of the Academy of Marketing Science 36(1), 18-20 (2008)

10. Massy, W.F., Sullivan, T.A., Mackie, C.: Data Needed for Improving Productivity Measurement in Higher Education. Research and Practice in Assessment 7, 5-15 (2012)

11. Parasuraman, A.: Service quality and productivity: a synergistic perspective. Managing Service Quality 12(1), 6-9 (2002)

12. Peppers, D., Rogers, M., Dorf, B.: Is your company ready for one-to-one marketing? Harvard Business Review 77, 151-160 (1999)

13. Singapore Ministry of Trade, Developing Singapore's education industry (2013), http://www.mti.gov.sg/../ERC_SVS_EDU_MainReport.pdf (Retrieved on November 14, 2013)

14. Saara, B.: A manufacturer becoming service provider - challenges and a paradox. Managing Service Quality 15(2), 142-155 (2005)

15. Spohrer, J., Maglio, P.P., Bailey, J., Gruhl, D.: Steps Toward a Science of Service Systems. Computer 40, 71-77 (2007)

16. Sphorer, J., Fodell, D., Murphy, W.: Ten Reasons Service Science Matters to Universities, Educause Review Online (2012), http : / /www . educause. edu / ero/article / ten-reasons-service-science-matters-universities (retrieved on November 9, 2013)

17. Vargo, S.L., Akaka, M.A.: Service-Dominant Logic as a Foundation for Service Science: Clarifications. Service Science 1(1), 32-41 (2009) 